\title{
Management algorithm of external fixation in lower leg arterial injury for limb salvages
}

\author{
Lei Jin ${ }^{1,2+}$, Song Zhang ${ }^{3+}$, Yuxuan Zhang ${ }^{2}$, Xin Lin ${ }^{1}$, Dehong Feng ${ }^{4,5^{*}}$ and Kejia Hu ${ }^{5,6^{*}}$
}

\begin{abstract}
Purpose: The aim of this study is to investigate the outcome of these limb-threatening injuries through external fixation treatment and to discuss the case of patients' functional recovery after external fixation.

Methods: Demographics, surgical treatment and outcomes in 88 patients with lower leg arterial injuries treated by external fixation at two trauma centers from 2009 to 2018 were reviewed. The primary outcome was the rate of successful lower leg salvage, while secondary outcomes were complications and functional recovery.

Results: Eighty-eight patients were identified and 80 patients (90 legs) maintained a successful lower leg salvage. The mean age was $32.7 \pm 10.8$ years, and $81.8 \%$ were male. The primary outcomes included the following complications: pin-tract infection (8 legs), pins loosening (4 pins), wound superficial infection (7 legs), deep infection developed osteomyelitis (3 legs), bone nonunion or bone defect (17 legs) and amputation (8 legs). The average healing time of fracture was $5.6 \pm 4.3$ months. The maintain of external fixation average time was $5.8 \pm 3.6$ months. The improvement of scores of the pain, function and quality of life in our follow-up was statistically significant.
\end{abstract}

Conclusion: For the lower extremity fracture patients with vascular injuries, using external fixation correctly can improve clinical outcomes and produce the improvement of pain, function and the quality of life.

Level of evidence: Retrospective cohort, level IV.

\section{Highlights}

- The success rate of the lower leg salvage is high, reach the percentage of 91.8\% (90/98).

- External fixation is less invasive, with achieving adequate stability to repair the arterial injury timely, can lower the ischemic time, and beneficial for the following bone or soft tissue repair.

- Treating the patients with external fixators timely is beneficial to the following vascular anticoagulation, bone defect and vein graft, as a result, the protection of lower limb can be improved.

Keywords: External fixation, Lower legs, Arterial injury, Bone nonunion, Flap transfer

*Correspondence: fengdh_wuxiph@sina.cn; dockejiahu@gmail.com

${ }^{\dagger}$ Lei Jin and Song Zhang contributed equally to this work

${ }^{5}$ Laboratory of Digital Medicine, Wuxi People's Hospital, Nanjing Medical

University, Wuxi 214023, China

Full list of author information is available at the end of the article

\section{Introduction}

Limb loss following lower leg arterial injury is common and has serious implications for the patient's life and functionality. The lower leg arterial injury is sometimes accompanied by comminuted fracture, severe wound contamination, etc. It can easily lead to severe complications such as compartment syndrome, bone exposure 
infection, amputation, which can lead to damage to patients' life, and limb salvage is critically dependent on ischemic time [1].

External fixation for lower limb fractures is an essential tool in the armamentarium of the trauma surgeon in acute trauma $[2,3]$. The main indication is to control damage through temporary fracture stabilization. The goal is to safeguard and reconstruct the alignment, length, and rotation of the fractured limb [2]. The use of external fixation is less invasive, can achieve adequate stability, and provide good access for wound management without compromising stability [4].

Previous studies indicated that limb loss after lower leg arterial injury was fatal if left untreated or treated untimely. The use of external fixation can yield excellent stability to allow the vascular repair to be performed in a controlled environment to protect the completed vascular repair from disruption [5]. Nevertheless, the current research paid more attention to the complex lower extremity deformity correction [6-9], the modification for external fixation [10-12] or case report of the use of external fixators in fractures [11]. However, according to our knowledge, to date, there has been no published work regarding the outcome of the treatment of external fixators in lower extremity arterial injuries. In other words, this is quite difficult to access the effects of external fixators used in treating lower limb arterial injuries.

The aim of this study is to investigate the limb salvage outcome, functional results of these limb-threatening injuries through external fixation treatment, and to discuss the case of patients' functional recovery after external fixation.

\section{Materials and methods}

From January 2010 to December 2018, trauma patients with lower leg arterial injury which surgically treated with external fixation by the Microsurgery team in two level 1 trauma centers (Wuxi People's Hospital and Wuxi Orthopedic Hospital) were retrospectively included. This study was performed with institutional review board approval in accordance with the Helsinki Doctrine.

Two separate reviewers performed the data collection, recording patient demographics, medical comorbidities, injury mechanism, Gustilo-Anderson classification [13], mangled extremity severity score (MESS) [14], injury severity score (ISS) [15], AIS abbreviated injury scale [16], time to surgery, flap use in soft-tissue reconstruction, follow-up time, and postoperative complication. The primary outcome of interest was lower leg salvage. Secondary outcomes included complications and functional recovery. And we use the Lower Extremity Functional Scale (LEFS) to evaluate the functional recovery of lower limbs, the Visual Analogue Scale (VAS) and the
Quality of Life Scale (QOL) to evaluate pain and life quality correspondingly.

Statistical analyses were performed using Stata version 14.0 MP (StataCorp) to assess for differences in patient demographics, injury characteristics, treatment course, and complications. The Kolmogorov-Smirnoff test was used to test whether the data were normally distributed. Normally distributed data were expressed as a mean \pm standard deviation, and skewed data were expressed as median (interquartile range). F-test was used for homogeneity of variance, independent samples $\mathrm{t}$-test for equal variance, and the non-parametric test was used for unequal variance. $\mathrm{P}<0.05$ was considered statistically significant.

\section{Results}

\section{Patients demographics}

Eighty-eight patients (98 legs) were diagnosed with a lower leg arterial injury with an unstable bone fracture or knee dislocation, which surgically treated with external fixation was included in the study. Table 1 presents the demographic data for the study population: age, gender, etc.

Patients who suffered from lower leg atrial injuries with an unstable bone fracture or dislocation were classified into open injury and closed injury. Then, all the patients were treated with external fixation. And our study used Primary end-to-end anastomosis and Autologous Vein Graft to repair the artery. Lastly, we classified the wound closure into different situations (Fig. 1).

\section{Primary outcomes}

External fixation (including mono lateral and circular Fixators) was performed in all the 88 patients prior to arteries repair. We divided the patients into different parts by Gustilo classification. An example of the classification was presented (Fig. 2).

Primary end-to-end anastomosis under the microscope was preferred in 42 patients. Autologous vein graft from the contralateral leg was used in 46 patients due to the artery was shortened after thorough debridement (Fig. 3).

No patients died in this study, 8 patients (8 legs) underwent secondary amputation due to the onset of artery blood-circulation crisis postoperatively, no sign of revascularization after being treated by spasmolytic medicine, or transplantation of the contralateral greater saphenous vein. All the 8 patients were in a poor general condition, who had a MESS score of 8 or above (Table 2).

Eighty patients (90 legs) obtained successful limb salvage, and the salvage rate was $91.8 \% .80$ patients were followed up for 12 months to 3 years, with an average of $15.5 \pm 5.5$ months. The external fixation time was 4 to 12 months, with an average of $5.8 \pm 3.6$ months. The 
Table 1 Demographics of patients with lower leg arterial injury

\begin{tabular}{|c|c|}
\hline Demographics & Case $(\mathrm{N}=\mathbf{8 8})$ \\
\hline Age, years, mean $\pm S D$ & $32.7 \pm 10.8,($ range $16-65)$ \\
\hline \multicolumn{2}{|l|}{ Gender } \\
\hline Males & 72 \\
\hline Females & 16 \\
\hline \multicolumn{2}{|l|}{ The mechanisms of injury } \\
\hline Motor vehicle accident trauma & 40 \\
\hline Bruise injury caused by heavy objects & 34 \\
\hline Falling injury & 3 \\
\hline Twist injury by working machines & 8 \\
\hline Cutting injury & 1 \\
\hline Explosion injury & 2 \\
\hline \multicolumn{2}{|l|}{ The types of arterial injury } \\
\hline Popliteal artery & 35 (36 legs) \\
\hline Anterior tibial artery & 16 (20 legs) \\
\hline Posterior tibial artery & 17 (20 legs) \\
\hline Anterior and posterior tibial artery & 20 (22 legs) \\
\hline \multicolumn{2}{|l|}{ The types of skeletal fracture } \\
\hline Upper $1 / 3$ tib/fib & 40 (44 legs) \\
\hline Middle 1/3 tib/fib & 18 (22 legs) \\
\hline Distal 1/3 tib/fib & 28 (30 legs) \\
\hline Traumatic knee dislocation & 2 (2 legs) \\
\hline \multicolumn{2}{|l|}{ Soft tissue injury } \\
\hline Open (Gustilo IIIc) & 80 (88 legs) \\
\hline Closed & 8 (10 legs) \\
\hline \multicolumn{2}{|l|}{ Injury evaluation } \\
\hline AIS score, mean \pm SD & $10.1 \pm 1.0,($ range $9-12)$ \\
\hline MESS score, mean \pm SD & $5.8 \pm 1.4$ (range $2-10)$ \\
\hline ISS score, mean \pm SD & $18.5 \pm 2.5$, (range $15-22)$ \\
\hline Injury to Surgery time, hours, mean \pm SD & $5.5 \pm 3.2,($ range $3-12)$ \\
\hline
\end{tabular}

$\mathrm{N}$ number of patients, SD standard deviation, AIS abbreviated injury scale, MESS mangled extremity severity score, ISS injury severity score; Data were reported as the number (injured legs) of patients except where noted

average healing time of fracture was $5.6 \pm 4.3$ months, ranging from 3 to 13 months.

\section{Complications}

Minor complications included pin-tract infection, pins loosening and wound superficial infection.

Three patients (3 legs) with a deep infection developed osteomyelitis, treatment involved thorough debridement, sequestrectomy and bone cement placement with Vancomycin, when the infection was quiescent as indicated by inflammatory parameters at least 1 year later, removal of External fixation and bone grafting with internal plating fixation was performed. All of them got bone union postoperatively in 7 to 15 months, with an average of $10.6 \pm 2.1$ months.

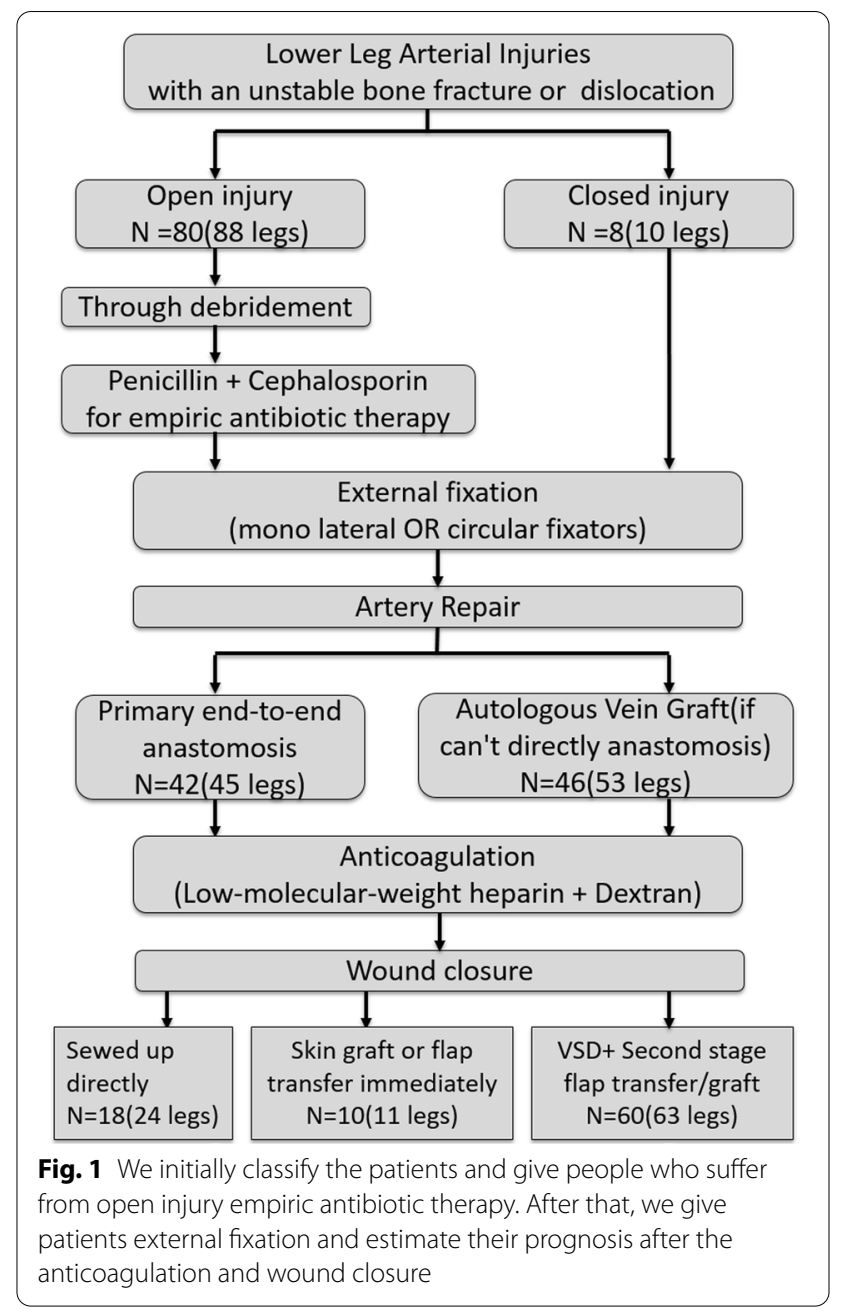

Sixteen patients (17 legs) suffered bone nonunion, 6 to 12 months after wound healing, patients were performed removal of External fixation, internal plating fixation replacing and bone grafting or bone transporting, all of them got bone union postoperatively in 5 to 14 months, with an average of $9.2 \pm 3.2$ months. Among them, 5 patients (5 legs) who had unilateral limb shortening experienced surgery. The length of the tibial bone defect was $4.5-14.0 \mathrm{~cm}$ with an average of $7.2 \pm 3.8 \mathrm{~cm}$ (Fig. 4).

Limb shortening-lengthening method using Ilizarov technique (external circular Fixators) was applied. At the time of the latest follow-up, all patients had shortened length less than $2 \mathrm{~cm}$ (Fig. 5).

\section{Functional recovery}

The LEFS was used to evaluate the functional recovery of lower limbs with artery injuries in 80 patients (90 legs), while pain and quality of life were accessed by VAS and 


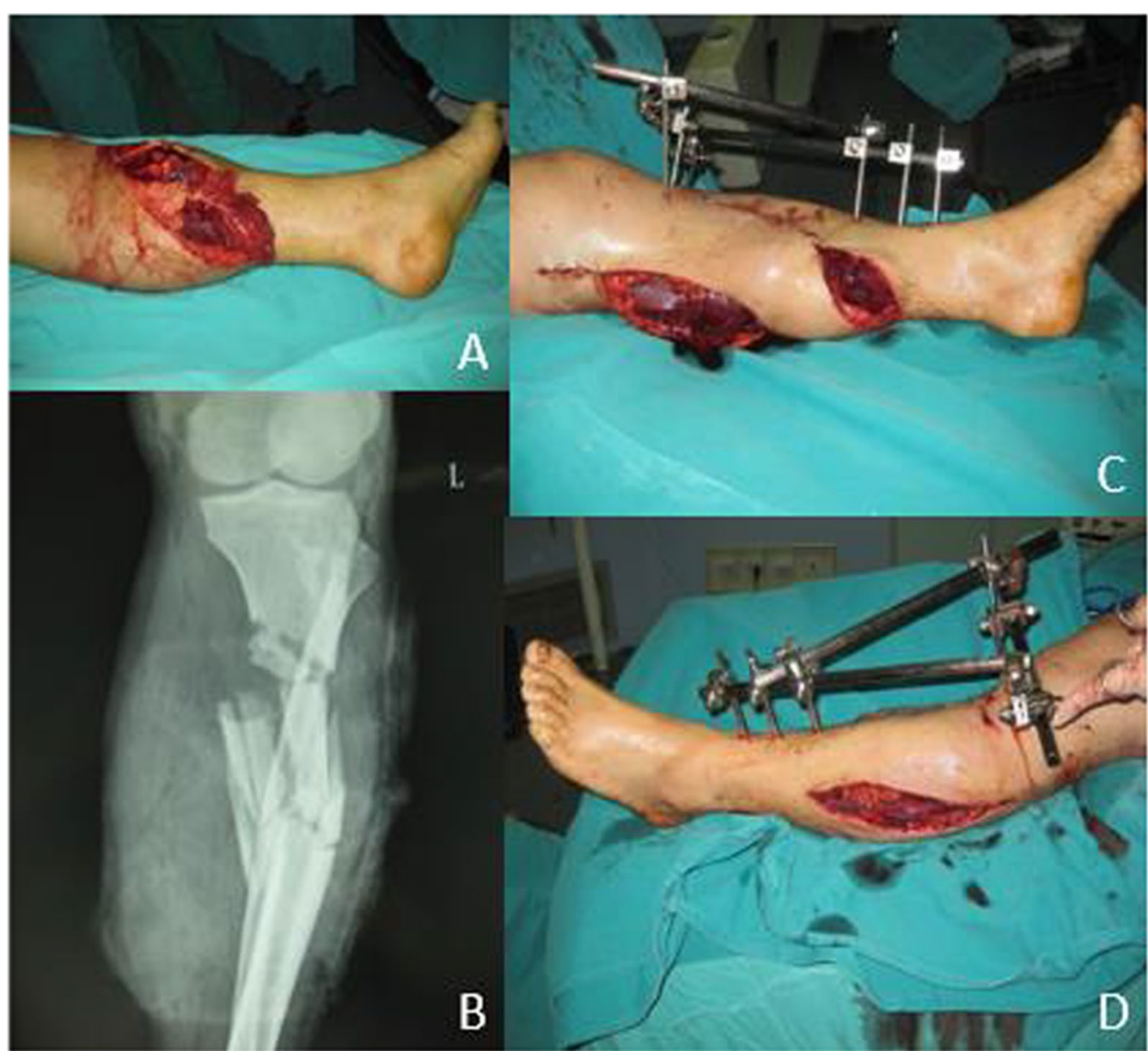

Fig. 2 An example of the classification and the application of external fixation. A The patient was classified as type Illc by Gustilo classification. B The preoperative radiograph showed an open comminuted fracture of the left tibia and fibula. C, D External fixation was used
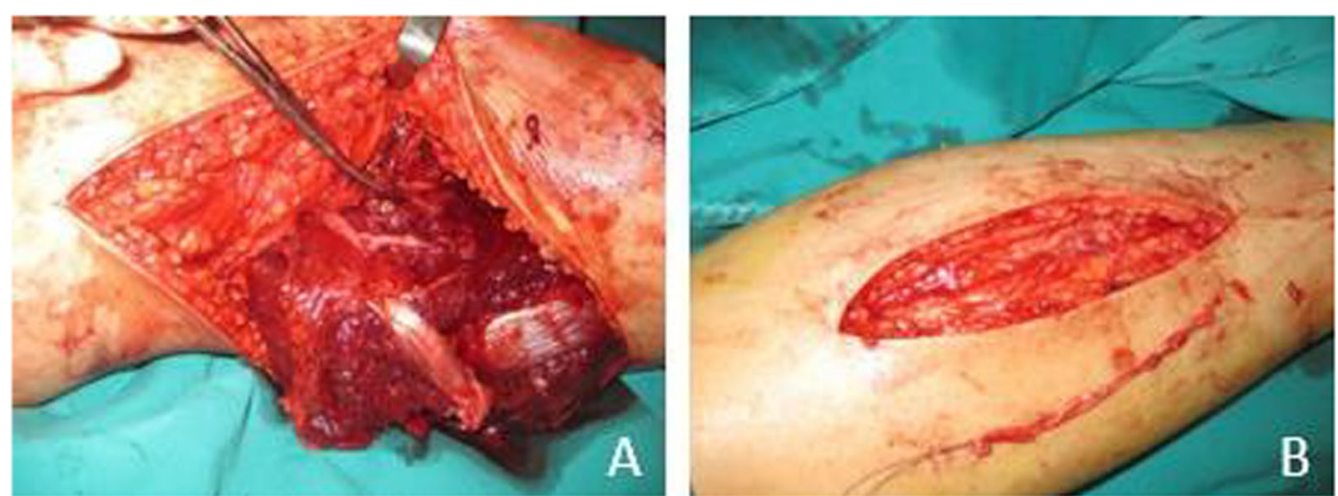

Fig. 3 A The popliteal artery was completely lacerated and shortened. B Autologous vein graft from the contralateral leg was performed

QOL scale separately. The survey measurements of the scales were shown below (Fig. 6). All three scales tend to be improved overall three follow-up time points.
The functional outcome of 70 patients (78 legs) following reconstruction with free tissue transfer or bony union was evaluated using the Enneking score system 
Table 2 Complications of lower leg arterial injury patients treated with external fixation

\begin{tabular}{|c|c|c|}
\hline Complication & N (45 legs) & Treatment \\
\hline Pin tract infection & 6 (8 legs) & Effective antibiotics \\
\hline Pins loosening & 2 (2 legs) & Exchanged the pins \\
\hline \multicolumn{3}{|l|}{ Post-operative wound } \\
\hline Superficial infection & 7 (7 legs) & Effective antibiotics \\
\hline Deep infection developed osteomyelitis & 3 (3 legs) & $\begin{array}{l}\text { Thorough debridement, sequestrectomy } \\
\text { and bone cement placement with vanco- } \\
\text { mycin }\end{array}$ \\
\hline Bone nonunion or bone defect & 16 (17 legs) & Bone grafting or bone transporting \\
\hline Crisis of blood-circulation & 8 (8 legs) & Amputation \\
\hline
\end{tabular}

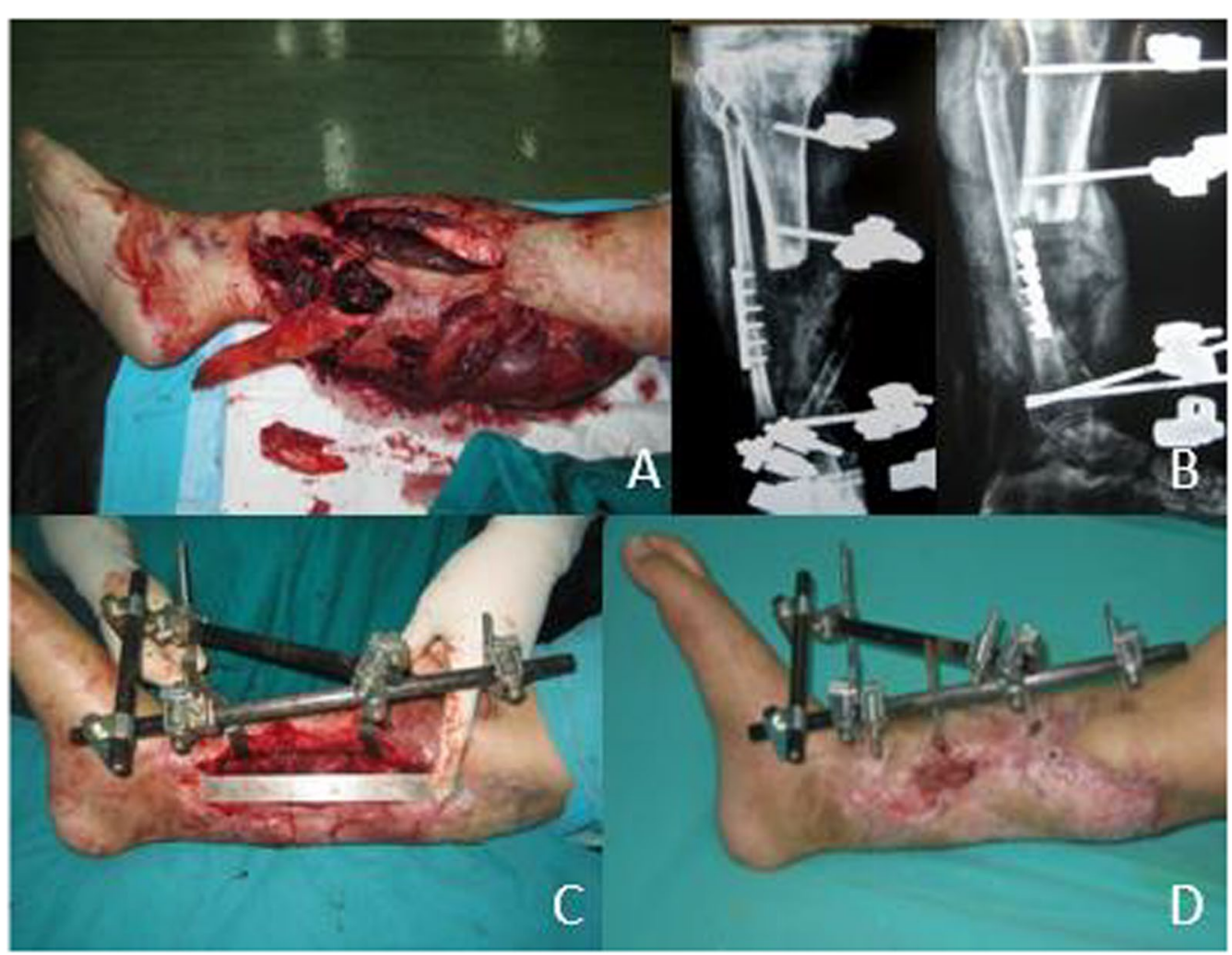

Fig. 4 The use of external fixation and the outcome of the patient from Fig. 3. A The patient was classified as type Illc by Gustilo classification. B External fixation was used after vascular repair. C 12 months postoperative appearance after external fixation. D The tibia was shortened about $14 \mathrm{~cm}$

[17]. The latter is determined by clinical examination and based on an assessment of the degree of physical disability and psychological acceptance of the reconstruction. The Enneking score is expressed as a percentage of the non-injured contralateral limb and was measured routinely at the orthopedic clinics. The mean Enneking score for patients with vascular injury was $23.8 \pm 12.5$, with a range of 7 to 38 (Fig. 7).
Figure 8 showed the recovery of the lower leg of the patient who had arterial injuries in Fig. 4. After a year and a half of recovery, the patient's leg regained normal physiological function. 


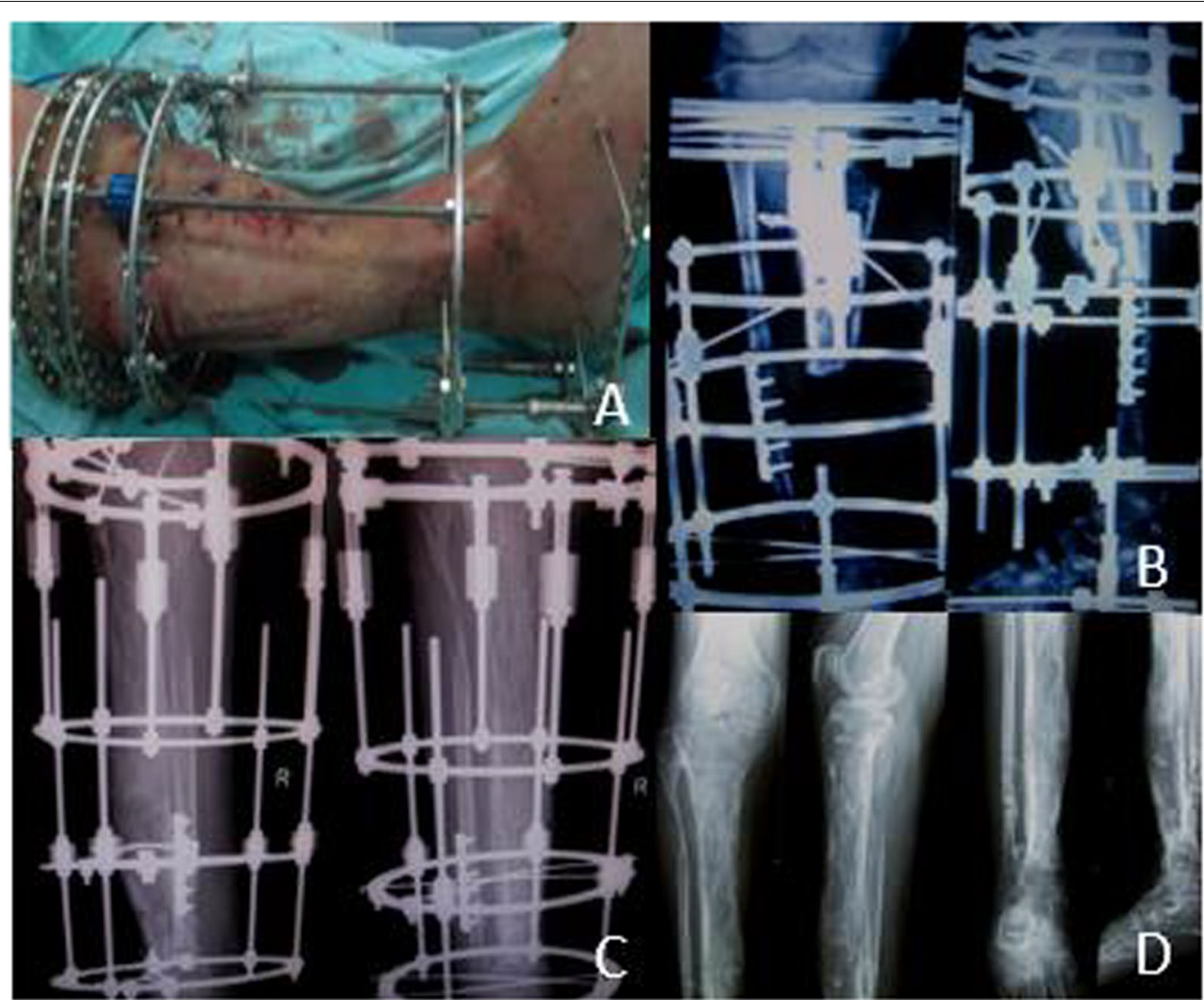

Fig. 5 Imaging method was used to evaluate the prognosis of the patients. A Most of the wound was closed during shortening-lengthening operation. B Postoperative radiograph showed a good external fixation. C, D Anteroposterior and lateral X-ray film at 12 months after operation, and after the removal of fixators

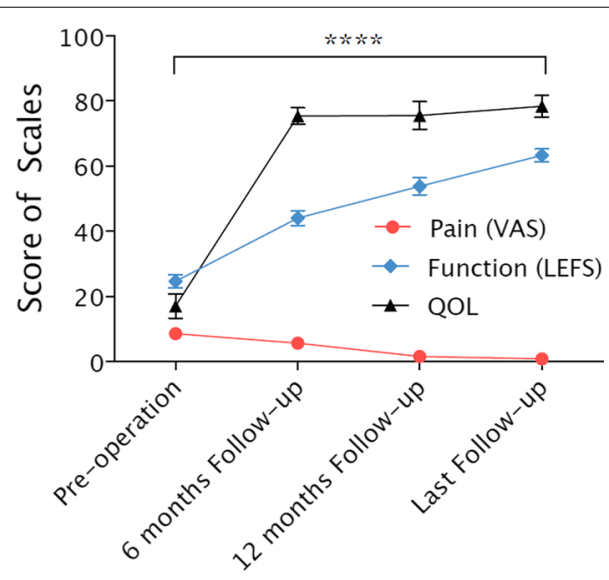

Fig. 6 The scale of VAS, LEFS, QOL from the pre-operation to follow-up time. The VAS, LEFS and QOL score of the patient from Fig. 4 were detected and statistical tests were conducted. We can see the tendency of the scores: the VAS score was decreased, whether the LEFS and QOL scores were increased over time. Statistical tests were conducted on the three groups of data, and it had a statistical difference between the group (pre-operation) and the group (last follow-up)

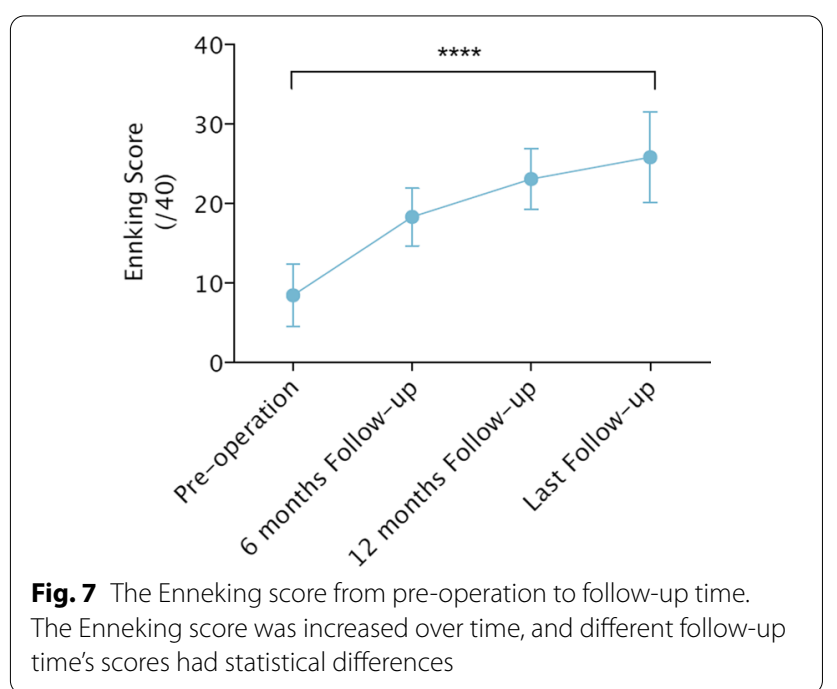




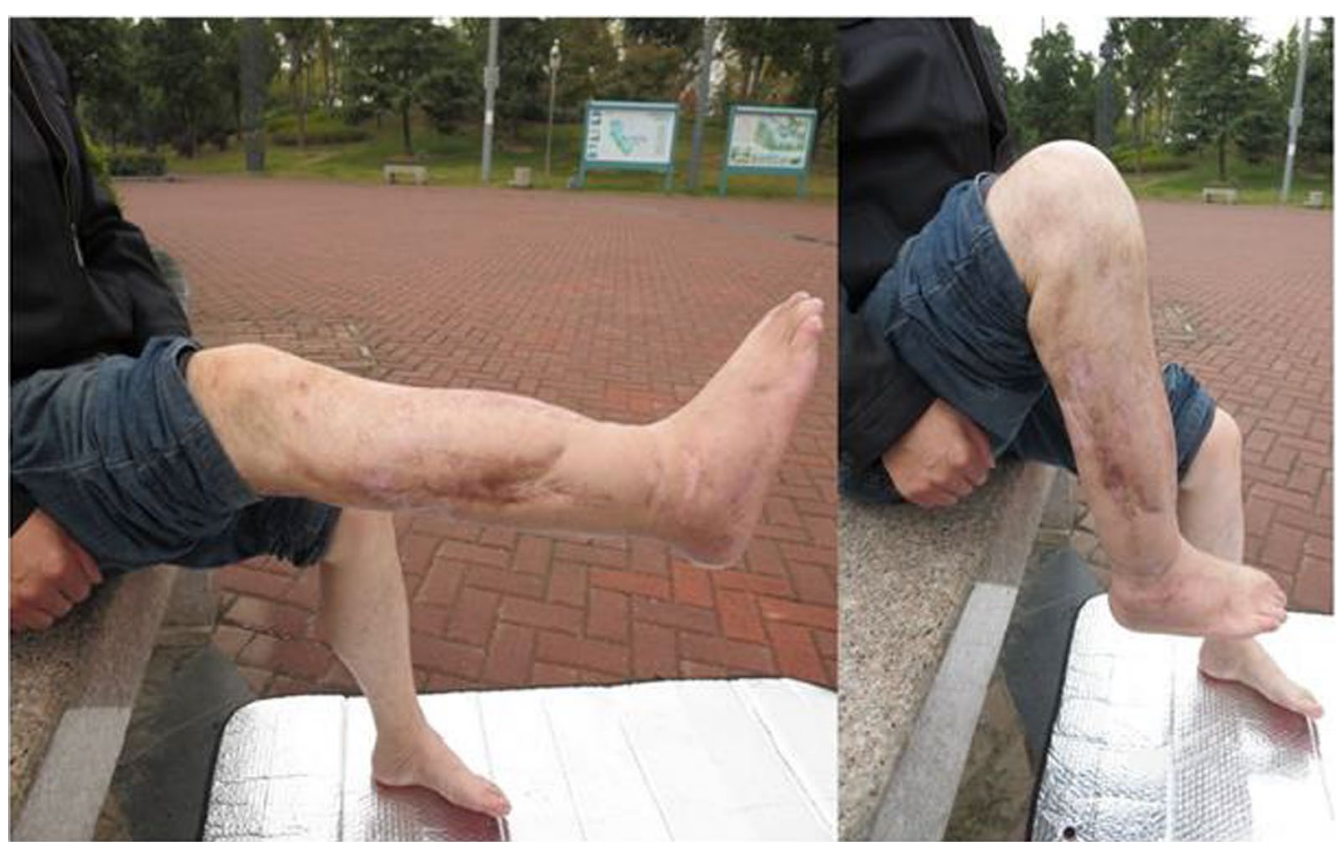

Fig. 8 Patients shown in Fig. 4 had equal limb length at 18 months postoperatively. The functions of the knee and ankle were good, with an Enneking score of 30

\section{Discussion}

Early fracture stabilization has many advantages: the procedure facilitates patient mobility, improves pulmonary toilet, decreases pain and thus the need for narcotics, decreases inflammatory mediator response and thromboembolic phenomena [18]. Using external fixation is less invasive, can achieve adequate stability, and provides good wound management access without compromising stability [4].

Our study aimed to investigate the limb salvage outcome, functional results of these limb-threatening injuries through external fixation treatment, and to discuss the case of patients' functional recovery after external fixation. In our study, we revealed that the use of external fixation had a high success rate of salvage, a low incidence rate of complications. Our results also showed a decrease in pain and improved quality of life and function, and these changes remained stable at follow-up.

Treatments for surgical stabilization of lower extremity fractures included plate fixation, intramedullary nailing with or without reaming, and external fixation. The traditional static immobilization using a plate and screw system carried a high fixation failure rate [19]. And compared with external fixation, the former treatments entailed greater blood loss and required increased operative time [18]. Today, lower extremity fracture patients with vascular injuries are treated mainly by plate fixation and intramedullary nailing (with or without reaming).
So far, no studies have investigated the outcome of using external fixation treating lower limb fracture patients with vascular injuries. Similarly, these patients' functional recovery (follow-up) has not been investigated.

The selection of either anastomosis or autologous vein graft in lower extremity fracture patients with vascular injuries has been studied extensively. Traditionally, in free flap cover of lower limb injuries, performing anastomoses proximal to the zone of injury was recommended [20]. And autologous vein graft was used when anastomosis cannot be performed. Our study supposed that end-toend anastomosis under the microscope is highly recommended in patients with vascular injuries. If interposition grafts are required, autologous vein graft is preferable to synthetic material, because a reversed saphenous vein graft from the contralateral limb has clearly superior patency rates, also can avoid foreign body in vivo [21-23]. Also, it is necessary to use computed tomography angiography to verify the area of vascular injuries [24]. But we should pay attention to the timing of the angiography. Asterios and his colleagues suggested that intraoperative arteriography should be used in patients with vascular injuries instead of preoperative diagnostic arteriography [25]. We agree with their view that intraoperative arteriography can be performed easily and quickly and is also noninvasive and requires less radiation [26]. This approach can be time-saving, which is vital in saving patients' limbs and their lives. 
Except for the selection for arterial repair and the use of angiography, re-vascularization is another significant factor related to long-term functional outcomes. Previous study [27] introduced the concept of the 6-h rule for re-vascularization, and most authors used $6 \mathrm{~h}$ as the definition of early intervention. However, skeletal muscle and nerve are, in fact, even more sensitive to ischaemia [28, 29]. Glass et al [30] in a Kaplan-Meier survival curve analysis, demonstrated that limb salvage begins to fall almost immediately the time when any further delay results in a rapid decline in survival, which begins at about 3-4 h. So, the time of re-vascularization should be as short as possible to minimize ischemia time and re-perfusion time, thus preventing potential necrotic changes and ischemia reperfusion injury, which is the key to limb salvage.

We should pay more attention to complications in using external fixators. Pin tract infection is one of the most common complications of external fixation. Occurring in $10.3 \%$ of our patients is comparable to those of $9.4 \%$ to $30 \%$ reported by other studies [31, 32]. Infection varies from minor inflammation remedied by local wound care,to superficial infection requiring antibiotics, local wound care, and occasional pin removal; to osteomyelitis requiring sequestrectomy. Higher rates of pin tract infection are seen when the pins are placed through large volumes of soft tissue (for example, thigh) [4]. A potential explanation is that pins placed within the zone of injury allowed bacteria to invade potential space created by soft-tissue disruption. So external fixator pins should be applied outside the zone of injury to span the zone of injury to minimize soft-tissue insult.

Pin-bone interface loosening or failure mainly with bone resorption around needles, full weight-bearing too early, fracture gaps $>2 \mathrm{~mm}$ of unstable fracture, osteoporosis, etc. External fixation failure includes the pins and link rod crack and bending deformation. Repeating bending makes the metal fatigue, which is a major cause of external fixation failure [33].

Another two common complications of external fixation are bone nonunion and deep infection developed osteomyelitis. For the bone nonunion, our study showed that bone nonunion rate was $20 \%(16 / 80)$, though we used the typical approach after removal of the external fixator, which included curettage, debridement, and irrigation of the pin sites with adjunctive antibiotic coverage [34]. One explanation could be that the original restoration was not satisfied, fracture gaps too large, and severe soft tissue injury. Cross and Swiontkowski [35] demonstrated as high as $13 \%$ bone nonunion rate using the external fixator, which was related to improper surgical technique, inaccurate fracture reduction, the initial severe trauma and the lack of elastic fixation changing in time. Menon [36] demonstrated the early period static fixation, middle and later period elastic fixation could be beneficial to the bone union. So, the ideal fracture reduction should be performed as well as possible before placing pins, instead of excessive dependence on external fixator adjusting.

For the deep infection, it is among the most important problems of open fractures, and the wound environment is very suitable for the spread of bacteria and this rate can reach 52\% in Gustilo Type 3B injuries [37]. In our study, a low incidence of deep infection was observed (3.4\%). We agree with Bilir et al. and our study indicated that the place of antibiotherapy is essential in the accurate treatment of these patients [37].

Except for these complications, we pay attention to another severe complication: amputation. So far, there have been several studies investigating whether MESS or other scales can be used to predict the outcome of lower limb fracture patients. Lin et al. agreed with the idea that the $=$ threshold for immediate amputation can be raised from $M E S S=7$ to $M E S S=9$ [38]. Whether Zhou supposed that patients with MESS $>$ or $=7$ are more likely to undergo amputate their limbs [39]. However, Alexandra proposed that considering the significant advances in reconstructive techniques, decision-making in patients with a MESS of 7 or greater should be reevaluated for everyday clinical use [40]. Except for MESS, Gupta and his colleagues considered that Ganga hospital score (GHS) has an improved ability to determine amputation in IIIB open tibia fractures [41]. More interestingly, Andrew and his colleagues supposed that there was no significant difference between MESS values of amputees and those treated with limb salvage [42]. We supposed that high MESS score is related to the amputation, for high MESS score represents severe injuries to a certain extent. As for Gupta's viewpoint, we held the view that a 3-2-1 modification of the Gustilo type IIIB classification to incorporate degree of arterial injury should be proposed [43].

Functional recovery is also very important. In order to improve the long-term outcome for our patients, we designed several approaches. Firstly, we should use the external fixation properly. Our study suggests that we should choose the proper fixator to improve patients' prognosis rather than use external fixator without considering patients' situation. And we agree with the idea that we should pay attention to the dynamization of fracture fixation to improve the fracture healing process [44]. Secondly, the combination of external fixation and other fixations may be much more beneficial in patients. Zhao demonstrates that combined fixation is an effective and safe alternative for the management of open tibial diaphyseal fractures compared with external 
fixation [45]. In clinical application, we may choose the proper fixation method depending on types of fracture, ages of the patients, the MESS or other scores, etc. Thirdly, we should pay more attention to patients with high MESS scores and we should try to propose personalized treatment protocol. Lastly, emotional factors play an important role in influencing patients' prognosis. Previous studies showed that posttraumatic stress disorder, depression, and psychological disorders are common complications observed in patients with these devastating injuries [46, 47]. Lowering patients' emotional pressure may be beneficial to patients' prognosis.

Our study has some limitations. First, we didn't conduct a subgroup analysis subdivided by soft tissue injury or type of vascular injury. Thus, we may not able to propose a standard or a personalized treatment protocol. Second, a multivariate analysis was not performed in the entire patient population. As a result, we couldn't identify whether multiple factors affect the success rate of surgery, the rate of complications, the outcome of our patients, etc. That is what we're going to do next.

\section{Conclusion}

The external fixator has the advantages of reliable immobilization, can lower the possibility of fracture or dislocation in a short time, which creates a suitable environment for vascular repair and shortens limb ischemia time. By correctly judging the condition of limb ischemia, mastering the operation indications reasonably, and preventing complications, the use of external fixators to treat lower leg arterial injury can obtain better clinical effects. Here, we provide a relatively standardized process by which clinicians can correctly classify the fracture in order to apply appropriate external fixation methods to improve patients' prognosis.

\section{Acknowledgements}

This research was performed mainly at the Wuxi Hongqiao Hospital, Wuxi No.9 People's Hospital. We thank Motao Liu for assistance with the data analysis and revision of the manuscript.

\section{Authors' contributions}

$\mathrm{KH}$ and DF conceptualized the work. $L J$ and $\mathrm{YZ}$ carried out the study and collected the data. SZ analyzed and interpreted the data. SZ and KH wrote the manuscript. KH, XL and DF revised the manuscript critically. All authors read and approved the final manuscript.

\section{Funding}

This study was supported by Ruijin Hospital Guangci Excellence Youth Training Program (K.H, GCQN-2019-B10); Shanghai Pujiang Program (KH, 19PJ1407500), Shanghai Municipal Health Commission Clinical Study Special Fund (KH, 20194Y0067).

\section{Availability of data and materials}

The datasets used or analyzed to support the findings of this study are available from the corresponding author on reasonable request.

\section{Declarations}

Ethics approval and consent to participate

All subjects gave their written informed consent, and the local clinical research ethics committees from Wuxi Orthopedic Hospital, Wuxi People's Hospital and Wuxi Hongqiao Hospital approved the study separately.

\section{Consent for publication}

Not Applicable.

\section{Competing interests}

The authors declare no competing interests.

\section{Author details}

${ }^{1}$ Department of Orthopedics, Wuxi Hongqiao Hospital, Jiangnan University School of Medicine, Wuxi 214026, China. ${ }^{2}$ Department of Orthopedics, Wuxi Orthopedics Hospital, Soochow University, Wuxi 214062, China. ${ }^{3}$ School of Basic Medicine, Naval Medical University, Shanghai 200433, China. ${ }^{4}$ Department of Orthopedics, Wuxi People's Hospital, Nanjing Medical University, Wuxi 214023, China. ${ }^{5}$ Laboratory of Digital Medicine, Wuxi People's Hospital, Nanjing Medical University, Wuxi 214023, China. ${ }^{6}$ Ruijin Hospital, Shanghai Jiao Tong University School of Medicine, Shanghai 200025, China.

Received: 2 August 2021 Accepted: 17 January 2022

Published online: 03 March 2022

\section{References}

1. Kohli A, Singh G. Management of extremity vascular trauma: Jammu experience. Asian Cardiovasc Thorac Ann. 2008;16(3):212-4.

2. Tejwani N, Polonet D, Wolinsky PR. External fixation of tibial fractures. J Am Acad Orthop Surg. 2015;23(2):126-30.

3. Carroll EA, Koman LA. External fixation and temporary stabilization of femoral and tibial trauma. J Surg Orthop Adv. 2011;20(1):74-81.

4. Chandran P, Puttaswamaiah R, Dhillon M, Gill S. Management of complex open fracture injuries of the midfoot with external fixation. J Foot Ankle Surg. 2006;45(5):308-15.

5. lannacone WM, Taffet R, DeLong WG Jr, Born CT, Dalsey RM, Deutsch LS. Early exchange intramedullary nailing of distal femoral fractures with vascular injury initially stabilized with external fixation. J Trauma. 1994;37(3):446-51.

6. Zhong W, Lu S, Chai Y, Wen G, Wang C, Han P. One-stage reconstruction of complex lower extremity deformity combining llizarov external fixation and sural neurocutaneous flap. Ann Plast Surg. 2015;74(4):479-83.

7. Montpetit K, Hamdy RC, Dahan-Oliel N, Zhang X, Narayanan UG. Measurement of health-related quality of life in children undergoing external fixator treatment for lower limb deformities. J Pediatr Orthop. 2009;29(8):920-6.

8. Manner HM, Huebl M, Radler C, Ganger R, Petje G, Grill F. Accuracy of complex lower-limb deformity correction with external fixation: a comparison of the Taylor Spatial Frame with the Ilizarov ring fixator. J Child Orthop. 2007;1(1):55-61.

9. Ganjwala D, Shah S, Shah S. Ensuring precision in lower limb deformity correction through a combination of temporary external fixation followed by internal fixation: results of a retrospective study. Indian J Orthop. 2014;48(5):495-500.

10. Sawyer JR, Kelly DM, Rhodes LN, Beaty JH, Terry Canale S, Warner WC Jr. Use of a "kickstand" modification for external fixation of lower extremity fractures in children. J Child Orthop. 2011;5(1):63-7.

11. Oka Y, Kim WC, Yoshida T, et al. Hybrid fixation for paediatric femoral supracondylar fracture during circular external fixation of the lower limb. Strat Trauma Limb Reconstr. 2020;15(3):179-83.

12. Logan C, Hess A, Kwon JY. Damage control orthopaedics: Variability of construct design for external fixation of the lower extremity and implications on cost. Injury. 2015;46(8):1533-8.

13. Kim P, Leopold S. In brief: Gustilo-Anderson classification [corrected]. Clin Orthop Relat Res. 2012;470(11):3270-4. 
14. Behdad S, Rafiei MH, Taheri H, et al. Evaluation of Mangled Extremity Severity Score (MESS) as a predictor of lower limb amputation in children with trauma. Eur J Pediatr Surg. 2012;22(6):465-9.

15. Cahill L, Joughin B, Kwon W, et al. Multiplexed plasma immune mediator signatures can differentiate sepsis from noninfective SIRS: American Surgical Association 2020 Annual Meeting Paper. Ann Surg. 2020;272(4):604-10.

16. Mahajna A, Aboud N, Harbaji I, et al. Blunt and penetrating injuries caused by rubber bullets during the Israeli-Arab conflict in October, 2000: a retrospective study. Lancet (London, England). 2002;359(9320):1795-800.

17. Enneking WF, Dunham W, Gebhardt MC, Malawar M, Pritchard DJ. A system for the functional evaluation of reconstructive procedures after surgical treatment of tumors of the musculoskeletal system. Clin Orthop Relat Res. 1993;286:241-6.

18. Nowotarski PJ, Turen CH, Brumback RJ, Scarboro JM. Conversion of external fixation to intramedullary nailing for fractures of the shaft of the femur in multiply injured patients. J Bone Joint Surg Am. 2000;82(6):781-8.

19. Schollmeier G, Uhthoff HK, Sarkar K, Fukuhara K. Effects of immobilization on the capsule of the canine glenohumeral joint. A structural functional study. Clin Orthop Relat Res. 1994:304:37-42.

20. Bendon CL, Giele HP. Success of free flap anastomoses performed within the zone of trauma in acute lower limb reconstruction. J Plast Reconstr Aesthet Surg. 2016;69(7):888-93.

21. Keen RR, Meyer JP, Durham JR, et al. Autogenous vein graft repair of injured extremity arteries: early and late results with 134 consecutive patients. J Vasc Surg. 1991;13(5):664-8.

22. Martin LC, McKenney MG, Sosa JL, et al. Management of lower extremity arterial trauma. J Trauma. 1994;37(4):591-8.

23. Fainzilber G, Roy-Shapira A, Wall MJ Jr, Mattox KL. Predictors of amputation for popliteal artery injuries. Am J Surg. 1995;170(6):568-70.

24. Nemoto M, Ishikawa S, Kounoike N, Sugimoto T, Takeda A. Free flap transfer to preserve main arterial flow in early reconstruction of open fracture in the lower extremity. Plast Surg Int. 2015;2015:213892.

25. Katsamouris AN, Steriopoulos K, Katonis P, et al. Limb arterial injuries associated with limb fractures: clinical presentation, assessment and management. Eur J Vasc Endovasc Surg. 1995;9(1):64-70.

26. Boyce R, Singh K, Obremskey W. Acute management of traumatic knee dislocations for the generalist. J Am Acad Orthop Surg. 2015;23(12):761-8.

27. Malan E, Tattoni G. Physio- and anatomo-pathology of acute ischemia of the extremities. J Cardiovasc Surg. 1963;4:212-25.

28. Labbe R, Lindsay T, Walker PM. The extent and distribution of skeletal muscle necrosis after graded periods of complete ischemia. J Vasc Surg. 1987;6(2):152-7.

29. Forrest I, Lindsay T, Romaschin A, Walker P. The rate and distribution of muscle blood flow after prolonged ischemia. J Vasc Surg. 1989;10(1):83-8.

30. Glass GE, Pearse MF, Nanchahal J. Improving lower limb salvage following fractures with vascular injury: a systematic review and new management algorithm. J Plast Reconstr Aesth Surg. 2009;62(5):571-9.

31. Watson JT, Moed BR, Karges DE, Cramer KE. Pilon fractures. Treatment protocol based on severity of soft tissue injury. Clin Orthop Relat Res. 2000;375:78-90.

32. Egol KA, Tejwani NC, Capla EL, Wolinsky PL, Koval KJ. Staged management of high-energy proximal tibia fractures (OTA types 41 ): the results of a prospective, standardized protocol. J Orthop Trauma. 2005;19(7):448-55.

33. Cohn MR, Unnanuntana A, Pannu TJ, Warner SJ, Lane JM. Materials in fracture fixation. In: Ducheyne P, editor. Comprehensive biomaterials II. Elsevier: Oxford; 2017. p. 278-97.

34. Bhandari M, Zlowodzki M, Tornetta P III, Schmidt A, Templeman DC. Intramedullary nailing following external fixation in femoral and tibial shaft fractures. J Orthop Trauma. 2005;19(2):1.

35. Cross WW 3rd, Swiontkowski MF. Treatment principles in the management of open fractures. Indian J Orthop. 2008;42(4):377-86.

36. Menon DK, Dougall TW, Pool RD, Simonis RB. Augmentative llizarov external fixation after failure of diaphyseal union with intramedullary nailing. J Orthop Trauma. 2002;16(7):491-7.

37. Bilir M, Tekin SB. Evaluation of complications in patients with open fractures of the upper and lower extremity treated with internal fixation after the external fixation. Ulusal travma ve acil cerrahi dergisi $=$ Turkish journal of trauma \& emergency surgery: TJTES. 2020;26(6):865-9.
38. Lin CH, Wei FC, Levin LS, Su Jl, Yeh WL. The functional outcome of lowerextremity fractures with vascular injury. J Trauma. 1997;43(3):480-5.

39. Zhou FY, Guo XS, Gao WY, Chen XL, Li ZJ, Jiang LF. Clinical significance of MESS scoring system in the treatment of fractures of lower limb combined with vascular injuries. Zhongguo Gu Shang. 2010;23(6):445-7.

40. Fochtmann A, Mittlböck M, Binder H, Köttstorfer J, Hajdu S. Potential prognostic factors predicting secondary amputation in third-degree open lower limb fractures. J Trauma Acute Care Surg. 2014;76(4):1076-81.

41. Gupta A, Parikh S, Rajasekaran RB, Dheenadhayalan J, Devendra A, Rajasekaran S. Comparing the performance of different open injury scores in predicting salvage and amputation in type IIIB open tibia fractures. Int Orthop. 2020;44(9):1797-804

42. Sheean AJ, Krueger CA, Napierala MA, Stinner DJ, Hsu JR. Evaluation of the mangled extremity severity score in combat-related type III open tibia fracture. J Orthop Trauma. 2014;28(9):523-6.

43. Stranix JT, Lee $Z$ H, Jacoby A, et al. Not all gustilo type IIIB fractures are created equal: arterial injury impacts limb salvage outcomes. Plast Reconstr Surg. 2017:140(5):1033-41.

44. Claes L. Dynamization of fracture fixation: timing and methods. Unfallchirurg. 2018;121(1):3-9.

45. Hao ZC, Xia Y, Xia DM, Zhang YT, Xu SG. Treatment of open tibial diaphyseal fractures by external fixation combined with limited internal fixation versus simple external fixation: a retrospective cohort study. BMC Musculoskelet Disord. 2019;20(1):311.

46. Abulaiti A, Yilihamu Y, Yasheng T, Alike Y, Yusufu A. The psychological impact of external fixation using the llizarov or Orthofix LRS method to treat tibial osteomyelitis with a bone defect. Injury. 2017;48(12):2842-6.

47. van der Merwe L, Birkholtz F, Tetsworth K, Hohmann E. Functional and psychological outcomes of delayed lower limb amputation following failed lower limb reconstruction. Injury. 2016;47(8):1756-60.

\section{Publisher's Note}

Springer Nature remains neutral with regard to jurisdictional claims in published maps and institutional affiliations.

Ready to submit your research? Choose BMC and benefit from

- fast, convenient online submission

- thorough peer review by experienced researchers in your field

- rapid publication on acceptance

- support for research data, including large and complex data types

- gold Open Access which fosters wider collaboration and increased citations

- maximum visibility for your research: over $100 \mathrm{M}$ website views per year

At BMC, research is always in progress.

Learn more biomedcentral.com/submissions 